\title{
On Spillover Effect of Systemic Risk of Listed Securities Companies in China Based on Extended CoVaR Model
}

\author{
Ze-Jiong Zhou $\mathbb{D}^{1},{ }^{1}$ Shao-Kang Zhang $\mathbb{D}^{2},{ }^{2}$ Mei Zhang $\mathbb{D}^{3},{ }^{3}$ and Jia-Ming Zhu ${ }^{4}{ }^{4}$ \\ ${ }^{1}$ School of Economics, Anhui University of Finance and Economics, Bengbu 233030, Anhui, China \\ ${ }^{2}$ School of Finance, Anhui University of Finance and Economics, Bengbu 233030, Anhui, China \\ ${ }^{3}$ School of Marxism, Shanghai University of Finance and Economics, Shanghai 200433, China \\ ${ }^{4}$ School of Statistics and Applied Mathematics, Anhui University of Finance and Economics, Bengbu 233030, Anhui, China \\ Correspondence should be addressed to Jia-Ming Zhu; zhujm1973@163.com
}

Received 2 February 2021; Revised 23 February 2021; Accepted 12 March 2021; Published 26 March 2021

Academic Editor: Huihua Chen

Copyright $\odot 2021$ Ze-Jiong Zhou et al. This is an open access article distributed under the Creative Commons Attribution License, which permits unrestricted use, distribution, and reproduction in any medium, provided the original work is properly cited.

\begin{abstract}
Based on the daily data from January 2, 2019, to September 30,2020, this paper uses the extended CoVaR model to measure the spillover effect of systemic risk among top 10 securities companies by market value in China, All Share Brokerage Index, All Share Financials Index, All Share Insurance Index, and CSI Banks Index. The conclusions are as follows: (1) there are risk spillover effects among 10 securities companies, which are asymmetric and bidirectional and highly volatile in a short period of time; (2) the spillover effect of systematic risk of securities companies is not necessarily related to the market value of securities companies but has a strong relationship with the stock market; (3) there are risk spillover effects between the sample securities companies and the four major indexes, but there are significant differences in the size of the spillover effects; (4) the securities industry has a great risk spillover effect on the financial industry, but the risk spillover effect of other financial sectors on the securities industry is very small. Finally, we put forward countermeasures and suggestions.
\end{abstract}

\section{Introduction}

Once the systemic financial risk occurs, it will not only harm the financial field but also cause extremely serious losses to the macroeconomy and social wealth. Because of its complexity and strong infectivity, it is difficult to identify and measure systemic financial risk. In recent years, the contagion of financial risk in China has been increasing, and the possibility of systemic risk in financial field is increasing.

Since the 1990s, China has vigorously developed the direct financing market, and the securities industry has developed rapidly. As of June 30, 2020, China's 164 securities companies have total assets of 8.03 trillion yuan, net assets of 2.09 trillion yuan, net capital of 1.67 trillion yuan, customer transaction settlement fund balance of 1.64 trillion yuan, and total entrusted management capital of 1.183 billion yuan. However, the securities industry has the smallest size compared to the banking, insurance, and trust industries, and its financing channels are limited. At the same time, the market environment and policy constraints restrict the innovation of the securities industry. Traditional businesses such as securities brokerage and proprietary securities are still the main profit points of the securities industry, making the impact of the market easily spread to the securities industry. All these make the securities industry's antirisk ability relatively weak $[1,2]$. As time progresses, China's capital market has gradually become more open, which indicates that the development of securities industry will be faced with domestic and foreign risks. In addition, the deepening of the degree of mixed operation and promoting the registration system and other deepening reform measures in the securities industry have not only brought innovation and dividends but also increased the systematic risk of the securities industry.

Systemic risk can cause many market participants to suffer losses at the same time and spread rapidly in the market [3]. Compared with the risk of an individual risk, systemic risk has five basic characteristics: complexity, 
suddenness, rapid contagion, wide spread, and great harm [4]. Therefore, many scholars are committed to studying how to scientifically monitor and measure systemic financial risks and prevent and resolve risk spillovers.

At present, the research methods of risk spillover effect can be summarized as follows: one is the financial network model proposed by Allen and Gale [5]. The core idea of the theory is to study the structural characteristics of financial network by collecting the data of mutual exposure or transaction between financial institutions, so as to study the contagion effect of financial risks in the network. The second is the systematic marginal expected loss (MES) method proposed by Acharya. This method calculates the risk contribution of a single participant to the market when the crisis breaks out. This method can measure the loss of a single financial institution and its proportion in the whole market [6]. The third is the CoVaR model proposed by Adriany and Brunnermeier. The model measures the loss of other institutions or markets when there is risk in one institution or market [7]. Since CoVaR method uses highfrequency data modeling, it can sensitively capture the contagion of financial risks and compute the risk spillover effect in the financial network more realistically, so it has gradually become an important tool for measuring financial risk contagion and spillover effect [8].

In recent years, some scholars have revised CoVaR model and applied the improved model to the estimation of systemic risk. Rungporn Roengpity and others used the CoVaR method to find that every large Thai commercial bank has systemic risk spillovers to the banking system [9]. $\mathrm{Li}$ and Fan applied quantile regression to the estimation of the CoVaR value of the yield data of seven Chinese banks from October 15, 2006, to December 31, 2010. They found that state-owned banks are more prominent in systemic risk premium than joint-stock commercial banks [10]. Gauthier et al. used the CoVaR model to study the relationship between Canadian banks with different capital allocations and their systemic risk contributions. They found that imposing macroprudential requirements on bank capital can improve financial stability [11]. Bernardi et al. used the CoVaR model under Bayesian regression to explain the dynamic behavior of the tail of financial assets [12]. Lin et al. used the ARGARCH-CoVaR model to compute the systemic risk of Chinese insurance companies and found that China Life Insurance had the largest risk spillover effect [13]. Girardi and Tolga Ergun used the CoVaR value to analyze the systemic risks of the US financial industry, and the results shows that there is no linear relationship between the size of financial enterprises and the size of systemic risk [14]. Reboredo and Ugolini used the CoVaR-Copula model to study the different characteristics of systemic risks in the European sovereign debt market before and after the Greek debt crisis broke out. They found that the systemic risk of the crisis countries decreased after the crisis, while the systemic risk of Greece to the crisis countries increased, and the systemic risk to other countries decreased [15]. Härdle et al. applied generalized quantile regression to compute the CoVaR value of American financial companies, which organically combined financial tail events with network technology. According to the value of risk spillover, they ranked risk receivers and disseminators in the US financial market, and found that the risk of acceptance and transmission of depository institutions is greater, while insurance companies are less affected [16]. Xu et al. used the quantile regression method to estimate the CoVaR value of listed insurance companies in China. It shows that the intensity of risk spillover varies with different insurance companies; the higher the proportion of nontraditional insurance of insurance companies is, the greater the systemic risk is; solvency regulation has a significant effect on restraining the risk spillover level of insurance companies [17]. Yuan and Wang found that there were significant two-way risk spillovers among insurance companies and insurance industry, showing asymmetry and difference [18]. Long et al. calculated the CoVaR and $\triangle \mathrm{CoVaR}$ of the CSI 300 secondary industry index by constructing a time-varying t-copula function and found that the systemic risk contribution of large industries such as banking and energy is not as high as that of small-scale industries like food and beverage [19]. Yang et al., respectively, measured the systemic risks of 56 Chinese listed enterprises, including financial institutions and real estate companies, using the methods of VaR, MES, $\mathrm{CoVaR}$, and $\triangle \mathrm{CoVaR}$. The research shows that the level of systemic risk spillover in China is rising year by year, and the transmission center has changed correspondingly in the events of "bank money shortage" and "stock market circuit breaker mechanism" [20]. Li et al. used the $\Delta \mathrm{CoVaR}$ to study and found that the risk spillover effect of China's banking and insurance sectors is higher than that of the securities industry [21]. Wang and Yang used EVT-Copula-CoVaR model to compute the risk spillover in Chinese stock market and found that it has a two-way and asymmetric risk spillover effect with other countries along "the Belt and Road" [22]. Xu et al. applied the systemic risk network based on LASSO-CoVaR to study the systemic risk of Chinese financial institutions from 2010 to 2017 and found that, for even the same institution, its risk has changed in different periods [23]. Zhang and $\mathrm{Xu}$ used $\triangle \mathrm{CoVaR}$ to measure the systemic risk brought by China's listed banks participating in financial derivatives transactions. They found that the risk has increased compared to before participating, and the impact of interest rate derivatives on systemic risk was greater than that of foreign exchange derivatives [24]. Tiwari et al. used $\triangle \mathrm{CoVaR}$ and MES to capture system risk and found that the risk spillover of oil price changes in the securities markets of G7 countries increased with market turmoil [25].

To sum up, scholars' research on systemic risk measurement is more and more in-depth, and CoVaR model has been constantly expanded and improved. However, the existing research on risk spillover effect mainly focuses on commercial banks, insurance companies, or financial institutions as a whole, while there are few studies on securities companies and securities industry. In addition, most of the existing literatures using CoVaR model to measure systemic risk spillovers in the securities industry still remain on the basic $\mathrm{CoVaR}$ and $\triangle \mathrm{CoVaR}$ methods, which will not capture the data characteristics of financial time series well. 
Compared with the simple GARCH model, on the one hand, the GJR-GARCH model can more deeply describe the asymmetry of volatility spillover between markets and is superior to the GARCH model and other related models in describing volatility and forecasting [26]; on the other hand, the DCC-GARCH model overcomes the shortcomings of the previous multivariate GARCH model. It not only has good computational advantages and can be used to estimate the correlation coefficient matrix that was originally difficult to calculate due to its scale but also can be used to study the dynamic correlation between multiple assets under the influence of market information and policy guidance in different periods [27]. The DCC-GJR-GARCH model combines the DCC-GARCH model and the GJR-GARCH model and combines the advantages of the two models, making the fitting of financial time series more realistic and convenient. The DCC-GJR-GARCH-CoVaR model constructed on the basis of the DCC-GJR-GARCH model, uses the variance between the financial time series processed by the DCC-GARCH model, and calculates the CoVaR value representing the value of the risk spillover, which can well measure the size of the systemic risk spillover.

In view of this, we use the DCC-GJR-GARCH-CoVaR model to study the systemic risk spillover effect of listed securities companies and its changing rules, and the two-way risk spillover between them and the financial industry is comprehensively considered.

\section{Construction of DCC-GJR-GARCH- CoVaR Model}

This part first brings the basic definition of the CoVaR model into consideration, then explains how to use the DCC-GJRGARCH model to estimate the conditional variance of yield series, and finally introduces the estimation steps of $\mathrm{CoVaR}$ value and $\Delta \mathrm{CoVaR}$ value of yield series.

2.1. Introduction to CoVaR Model. Adrian and Brunnermeier [28] proposed CoVaR based on VaR. CoVaR is defined as when the loss $X^{i}$ of financial institutions is $\operatorname{VaR}_{q}^{i}$, under the confidence level of $q$, the $\mathrm{VaR}$ is faced by financial institution $j$, that is,

$$
\operatorname{Prob}\left(X^{j} \leq \operatorname{CoVaR}_{q}^{j \mid i} \mid X^{i}=\operatorname{VaR}_{q}^{i}\right)=q .
$$

Thus, the systemic risk spillover value $(\triangle \mathrm{CoVaR})$ of financial institution $i$ to financial institution $j$ or the whole system can be expressed as follows:

$$
\Delta \mathrm{CoVaR}_{q}^{j \mid i}=\mathrm{CoVaR}_{q}^{j \mid i}-\mathrm{VaR}_{q}^{j} .
$$

Among them, $\mathrm{VaR}_{q}^{j}$ is the value at risk faced by financial institution $i$ when it is not under extreme risk conditions.

2.2. Fitting Conditional Variance of DCC-GJR-GARCH Model. GARCH model can explain heteroscedasticity effect and volatility aggregation of financial time series. In addition, Engel's research found that the DCC-GARCH model can effectively resolve the difficulty in too many parameters in the multivariate GARCH model by allowing variable conditional correlation coefficients and meet the characteristics that the influence degree between financial time series is not fixed but changes with time [28]. The GJRGARCH model first introduced by Glosten et al., through bringing in the dummy variables, makes the parameters in the basic GARCH model can be negative [29]. Therefore, this article uses the DCC-GJR-GARCH model introduced by Glosten and other scholars to estimate the conditional variance.

We assume that the residual series $e_{t}$ of financial institutions' return series is white noise series, the covariance matrix is $H_{t}$, and $v$ is the degree of freedom of multivariate joint $t$ distribution:

$$
e_{t} \mid \Omega_{t-1} \sim T\left(0, H_{t}, \nu\right)
$$

where $\Omega_{t-1}$ represents the previous information set and $H_{t}$ is the covariance matrix, which can be expressed as

$$
H_{t}=D_{t} R_{t} D_{t},
$$

in which $D_{t}$ of equation (4) is the variance matrix of the residual error $e_{t}$, and it can be shown as follows:

$$
D_{t}=\operatorname{diag}\left(\sqrt{h_{11, t}}, \ldots, \sqrt{h_{n n, t}}\right) .
$$

Among them, $h_{i i, t}$ is the conditional variance of the residual error $e_{t}$, and it is characterized by $\operatorname{GARCH}(1,1)$, that is,

$$
h_{i i, t}=\omega_{i}+\alpha_{i} e_{i, t-1}^{2}+\beta_{i} h_{i i, t-1}+g I_{t-1} e_{i, t-1}^{2} .
$$

The expression of schematic function $I_{t-1}$ of equation (6) is as follows:

$$
I_{t-1}= \begin{cases}1, & e_{i, t-1}<0 \\ 0, & e_{i, t-1} \geq 0\end{cases}
$$

When there is good news in the market $\left(e_{i, t-1} \geq 0\right)$, the variance $h_{i i, t}$ is affected by $\alpha_{i}$. When the market appears in bad news $\left(e_{i, t-1}<0\right)$, the variance $h_{i i, t}$ is affected by $\left(\alpha_{i}+g\right) \cdot R_{t}$ of equation (4) is the dynamic correlation coefficient matrix. The expression is as follows:

$$
\begin{aligned}
R_{t} & =\operatorname{diag}\left(1 / \sqrt{q_{11, t}}, \ldots, 1 / \sqrt{q_{n n, t}}\right) * Q_{t} \\
& * \operatorname{diag}\left(1 / \sqrt{q_{11, t}}, \ldots, 1 / \sqrt{q_{n n, t}}\right),
\end{aligned}
$$

where $q_{n, t}$ is the conditional variance of standardized residuals. Therefore, the dynamic correlation coefficient $\left(\rho_{i j, t}\right)$ in $R_{t}$ is as follows: $\rho_{i j, t}=q_{i j, t} / \sqrt{q_{i i, t} q_{j j, t}} Q_{t}$ of equation (8) can be expressed as

$$
Q_{i}=(1-\alpha-\beta) \bar{Q}+\alpha \varepsilon_{t-1} \varepsilon_{t-1}+\beta Q_{t-1}
$$

where $\bar{Q}$ is the unconditional variance matrix of standardized residuals $\varepsilon_{t}$ and $\varepsilon_{t}=D_{t}^{-1} e_{t}$ is the vector normalized residuals.

For the positive definiteness of $H_{t}$, only $\alpha+\beta<1$ is required [30]. 
2.3. Estimation Steps of CoVaR. Based on the basic definition of CoVaR and the conditional variance fitted by the DCCGJR-GARCH model, we can estimate the CoVaR value and $\Delta \mathrm{CoVaR}$ value of the research object. The specific estimation steps are as follows: the first step is to collect the time series data of financial institutions and establish GARCH $(p, q)$ model to measure the volatility of their returns:

$$
\begin{aligned}
& r_{i, t}=\beta_{i}+\beta_{i, p} A_{p}(L) r_{i, t}-B_{p}(L) e_{i, t}, \\
& h_{i, t}^{2}=\gamma_{i}+\delta_{i} e_{i, j-1}^{2}+\theta_{i} h_{t-1}^{2} .
\end{aligned}
$$

Among them, $r_{i, t}$ is the yield of financial institution $i$ in period $t ; h_{i, t}^{2}$ is the variance of the residual error $e_{i, t}$ in the $t$ period; $e_{i, t-1}^{2}$ is the variance of the residual error $e_{i, t}$ in $t-1$ period, namely, ARCH term; $h_{t-1}^{2}$ denotes the GARCH term; and dummy variable $I_{t-1}$ represents the asymmetric effect of new information. $\beta_{i}$ and $\gamma_{i}$ are constant terms, and $A_{p}(L)$ and $B_{p}(L)$ are lagging operators.

In the second step, the GARCH model is used to estimate the $\mathrm{VaR}_{i}$ value of financial institutions. The formula is as follows:

$$
\mathrm{VaR}_{i, t}=-\widehat{r_{i, t}}+F^{-1}(q) \widehat{h_{i, t}} \text {. }
$$

Among them, $\widehat{r_{i, t}}$ is the one-step forward estimate of the return rate of financial institutions $i$ obtained by the GARCH model, and $\widehat{h_{i, t}}$ is the one-step forward estimation value of $h_{i i, t} \cdot F^{-1}$ is the inverse function of the distribution function of $t$ distribution, and $q$ is the confidence level [31].

In the third step, using the DCC-GJR-GARCH model and the results of the previous step, the CoVaR value of the mechanism $j$ under the influence of the mechanism $i$ and macrostate is constructed. The formula is as follows:

$$
\begin{aligned}
& r_{j, t}=\beta_{i}+\beta_{j, p} A_{p}(L) r_{j, t-t-} \theta_{j \mid i} r_{i, t}+\varphi_{j} r_{m, t-1}+B_{p}(L) e_{i, t}, \\
& h_{j, t}^{2}=\gamma_{j}+\delta_{j} e_{j, t-1}^{2}+\theta_{j} h_{t-1}^{2}+g I_{t-1} e_{j, t-1}^{2},
\end{aligned}
$$

where $r_{j, t}$ is the yield of financial institution $j$ and $r_{i, t}$ and $r_{m, t-1}$ represent the impact of financial institution $i$ and macrosituation on financial institution $j$, respectively. $A_{p}(L)$ and $B_{p}(L)$ are lag operators, and $\theta_{j \mid i}$ is the regression coefficient of financial institution $i$ in the formula. Introducing $r_{i, t}=\mathrm{VaR}_{i, t}$ into the mean value equation, the following formula is obtained:

$$
r_{j, t}=\beta_{i}+\beta_{j, p} A_{p}(L) r_{j, t-1}+\theta_{j \mid i} \mathrm{VaR}_{i, t}+\varphi_{j} r_{m, t-1}+B_{p}(L) e_{i, t} .
$$

According to the mean value $\widehat{r_{j, t}}$ and the conditional variance $\widehat{h_{j, t}}$, the CoVaR and $\Delta \mathrm{CoVaR}$ of financial institution $j$ are obtained. The formula is as follows:

$$
\begin{gathered}
\operatorname{CoVaR}_{j \mid i, q, t}=-\widehat{r_{j, t}}+F^{-1}(q) \widehat{h_{j, t}}, \\
\Delta \operatorname{CoVaR}_{j \mid i, q, t}=\operatorname{CoVaR}_{j \mid i, q, t}-\operatorname{VaR}_{i, q, t},
\end{gathered}
$$

where $\mathrm{VaR}_{i, q, t}$ is the same as the $\mathrm{VaR}_{i}$ value of financial institution $i$ calculated by formula (12).

\section{Empirical Analysis}

3.1. Data Selection and Processing. This paper uses the stock price index of the top 10 securities companies with total market value which listed in China's A-share market before January 1, 2019. They are GF Securities Co., Ltd. (000776.SZ), Guotai Junan Securities Co., Ltd. (601211.SH), Guosen Securities Co., Ltd. (002736.SZ), Haitong Securities Co., Ltd. (600837.SH), Huatai Securities Co., Ltd. (601688.SH), Shen Wan Hong Yuan Securities Co., Ltd. (000166.SZ), China Galaxy Securities Co., Ltd. (601881.SH), China Merchants Securities Co., Ltd. (600999.SH), China Securities Co., Ltd. (601066.SH), and Citic Securities Co., Ltd. (600030.SH), All Share Brokerage Index (399975. SZ) representing the securities industry, All Share Financials Index (000992. SH) representing the financial industry, All Share Insurance Index (h30186. CSI) representing the insurance industry, and CSI Banks Index (399986. SZ) representing the banking industry as a research sample, use the CSI 500 (000905. SH) index as a macrovariable, and choose the closing price on each trading day as the original data. The data selection time limit is from January 2, 2019, to September 30, 2020. All data are from Wind database.

The formula for calculating the daily return of sample companies stocks and the indexes is as follows:

$$
r_{t}=100 * \operatorname{In}\left(P_{t} / P_{t-1}\right) \text {. }
$$

Among them, $P_{t}$ is the closing price of the stocks or indexes on day $t$.

3.2. Descriptive Statistics of Data. We conducted descriptive statistics on the daily yield series of samples (see Table 1 for details).

According to Table 1, the average returns of 10 securities companies stocks are all greater than 0 . Among them, the largest average yield is the stock of China Securities Co., Ltd., reaching 0.4123; the smallest is the stock of Guotai Junan Securities Co., Ltd., which is 0.0497 . The standard deviation of the stock return sequences is generally more than 2 units larger than the mean and much larger for the mean between 0.05 and 0.4 , and the difference in the yield of the same stock can reach $20 \%$, which all shows that the returns of stocks have changed drastically. We can observe that the kurtosis of the stock return sequences of all securities companies are greater than 3, showing a certain degree of right deviation. The JB statistics are all very large, and the $P$ values are all less than 0.01, showing the characteristic of the financial time series with peaks and thick tails. Therefore, this paper chooses $t$ distribution to describe the stock return sequences, which is more consistent with the characteristics of the data itself.

Next, we conduct descriptive statistics on the daily yield series of the CSI 500 Index, All Share Financials Index, All Share Insurance Index, CSI Banks Index, and CSI 500 Index in the inspection period (see Table 2 for details).

According to Table 2, the average returns of 5 indexes are all greater than 0 , which is much smaller than the mean of the stocks of securities companies. Among them, the largest 
TABLE 1: Descriptive statistics of the yield series of securities companies stocks.

\begin{tabular}{|c|c|c|c|c|c|c|c|c|c|}
\hline Company & Mean & Median & Maximum & Minimum & Standard deviation & Skewness & Kurtosis & JB statistics & Probability \\
\hline$C 1$ & 0.0598 & $<0.0001$ & 9.5422 & -10.5286 & 2.2441 & 0.0213 & 7.7531 & 401.9827 & $<0.0001$ \\
\hline$C 2$ & 0.0497 & -0.0549 & 9.5311 & -10.5549 & 2.1246 & 0.2060 & 8.0790 & 461.9688 & $<0.0001$ \\
\hline$C 3$ & 0.1178 & -0.0779 & 9.5667 & -10.5356 & 2.4627 & 0.7192 & 6.6342 & 271.7902 & $<0.0001$ \\
\hline$C 4$ & 0.1137 & $<0.0001$ & 9.5667 & -10.5519 & 2.4939 & 0.5702 & 6.5403 & 246.1270 & $<0.0001$ \\
\hline C5 & 0.0622 & $<0.0001$ & 9.5535 & -10.5362 & 2.3897 & 0.1219 & 7.3420 & 336.4899 & $<0.0001$ \\
\hline C6 & 0.0680 & $<0.0001$ & 9.5476 & -10.4899 & 2.1731 & 0.3078 & 8.8717 & 620.1339 & $<0.0001$ \\
\hline$C 7$ & 0.1500 & $<0.0001$ & 9.5886 & -10.5169 & 2.9608 & 0.4116 & 5.3796 & 112.7984 & $<0.0001$ \\
\hline C8 & 0.1595 & $<0.0001$ & 9.5515 & -10.5064 & 2.3985 & 0.5500 & 7.5839 & 395.3759 & $<0.0001$ \\
\hline C9 & 0.4123 & $<0.0001$ & 9.5612 & -10.5548 & 3.8536 & 0.2803 & 3.9685 & 22.2787 & $<0.0001$ \\
\hline$C 10$ & 0.1546 & $<0.0001$ & 9.5449 & -10.5527 & 2.4953 & 0.3078 & 7.5561 & 376.0665 & $<0.0001$ \\
\hline
\end{tabular}

Note. C1, C2, .., C10 represent GF Securities Co., Ltd., Guotai Junan Securities Co., Ltd., Guosen Securities Co., Ltd., Haitong Securities Co., Ltd., Huatai Securities Co., Ltd., Shen Wan Hong Yuan Securities Co., Ltd., China Galaxy Securities Co., Ltd., China Merchants Securities Co., Ltd., China Securities Co., Ltd., and Citic Securities Co., Ltd., respectively. C1, C2, ., C10 in all tables below have the same meaning as this table.

Table 2: Descriptive statistics of the yield series of indexes.

\begin{tabular}{|c|c|c|c|c|c|c|c|c|c|}
\hline Index & Mean & Median & Maximum & Minimum & Standard deviation & Skewness & Kurtosis & JB statistics & Probability \\
\hline All Sh & 1196 & -0.0015 & 09 & -10.5251 & 2.3335 & 14 & 7.0 & 292 & $<0.0001$ \\
\hline All $S$ & 0.0544 & -0.0 & & & & & & & \\
\hline All Share Insurance Index & 0.0713 & -0.0350 & & & & & & 201 & 01 \\
\hline & 0.0158 & -0.0 & & & & 0.6 & & 123 & 001 \\
\hline CSI 500 Index & 0.0927 & 0.1136 & 5.4393 & -9.0811 & 1.6024 & -0.8732 & 7.2741 & 379.2824 & $<0.0001$ \\
\hline
\end{tabular}

average yield is the All Share Brokerage Index, reaching 0.1196; the smallest is CSI Banks Index, which is 0.0158 . Compared with the mean, the standard deviation of the yield series of indexes is still very large and is generally more than 1 unit higher than the mean between 0.01 and 0.1 , indicating that the yield of indexes has also changed drastically. The kurtosis of all yield series of indexes is all greater than 3 , and there is a certain degree of left or right deviation. The JB statistics are all large, and the $P$ values do not exceed 0.01 . The original hypothesis that the yield series is a Gaussian distribution is rejected at the $1 \%$ significance level, indicating that the $t$ distribution is better for describing the yield series of indexes.

3.3. Stability Test. When the variable is time series data, if it is not tested for stationarity, there may be pseudoregression in regression analysis. Here, we conduct the ADF test on the daily yield series of ten listed securities company stocks, CSI 500 Index, All Share Financials Index, All Share Insurance Index, CSI Bank Index, and All Share Brokerage Index during the inspection period (see Tables 3 and 4 for details).

According to Tables 3 and 4, whether it is the stock yield series of securities companies or the index yield series, their data during the inspection period have passed the ADF test, and the original hypothesis that the yield series have unit root is rejected by all results at the $1 \%$ significance level.

3.4. Autocorrelation Test. When the autocorrelation of random error term appears in time series data, the real variance of parameter estimation value will be underestimated, the value of $t$ statistic will be overestimated, and the original unimportant explanatory variables may be mistakenly considered important and retained, which will eventually lead to the reduction in the accuracy of the model prediction.

We use Eviews software to calculate the ACF value and PACF value of ten securities company stocks and five index yield series, and the original hypothesis that the series having autocorrelation is rejected by all results at the $5 \%$ significance level.

3.5. ARCH Effect Test. Engle [32] pointed out that heteroscedasticity may occur in time series data and thus proposed a method for observing variance changes in time series, namely, ARCH test method [33]. We assume the number of lag periods in the ARCH test is one and conduct the ARCH effect test on the daily yield series of ten securities company stocks and five indexes during the inspection period (see Tables 5 and 6 for details).

According to Table 5, the $P$ value of the $n * R$-squared statistic of the stock yield series of ten securities companies is all below 0.1 ; that is, the original hypothesis that the random error term of the yield series has no heteroscedasticity is rejected at the significance level of $10 \%$. The series have the $\mathrm{ARCH}$ effect under the assumption that the random error term lags for one period.

According to Table 6, in addition to the CSI 500 index, which is a macrovariable, in the test results, the $P$ values of the Obs. $n^{*}$ R-squared of the All Share Financials Index, All Share Insurance Index, CSI Banks Index, and All Share Brokerage Index yield series are all below 0.1, and the original hypothesis that the random error term of the yield series has no heteroscedasticity is rejected at the significance level of $10 \%$. The series have the ARCH effect.

3.6. Analysis of Systemic Risk Spillover Effect among Securities Companies. The analysis steps of systemic risk spillover effect among securities companies are as follows: first, use 
TABLE 3: ADF test of stock yield series of securities companies.

\begin{tabular}{lcccc}
\hline Company & Obs. & Prob. & Lag & 0 \\
C1 & 427 & $<0.0001$ & 0 & 17 \\
$C 2$ & 427 & $<0.0001$ & 0 & 17 \\
$C 3$ & 427 & $<0.0001$ & 0 & 17 \\
$C 4$ & 427 & $<0.0001$ & 0 & 17 \\
$C 5$ & 427 & $<0.0001$ & 0 & 17 \\
$C 6$ & 427 & $<0.0001$ & 0 & 17 \\
$C 7$ & 427 & $<0.0001$ & 0 & 17 \\
$C 8$ & 427 & $<0.0001$ & 0 & 17 \\
$C 9$ & 427 & $<0.0001$ & 0 & 17 \\
$C 10$ & 427 & $<0.0001$ & 0 \\
\hline
\end{tabular}

TABLE 4: ADF test of index yield series.

\begin{tabular}{lcccc}
\hline Index & Obs. & Prob. & Lag & Max lag \\
\hline All Share Brokerage Index & 427 & $<0.0001$ & 0 & 17 \\
All Share Financials Index & 427 & $<0.0001$ & 0 & 0 \\
All Share Insurance Index & 427 & $<0.0001$ & 0 & 17 \\
CSI Banks Index & 427 & $<0.0001$ & 0 & 17 \\
CSI 500 Index & 427 & $<0.0001$ & 0 & 17 \\
\hline
\end{tabular}

TABLE 5: ARCH test of stock yield series of securities companies.

\begin{tabular}{lcccc}
\hline Company & $F$-statistic & Prob. $F$ & Obs. *R-squared & Prob. chi-square $(1)$ \\
\hline$C 1$ & 16.6167 & 0.0001 & 16.0655 & 0.0001 \\
$C 2$ & 28.6064 & $<0.0001$ & 26.9248 & $<0.0001$ \\
$C 3$ & 9.4442 & 0.0023 & 9.2820 & 0.0023 \\
$C 4$ & 8.3751 & 0.0040 & 8.2516 & 0.0041 \\
$C 5$ & 12.9090 & 0.0004 & 12.5866 & 0.0004 \\
$C 6$ & 34.3025 & $<0.0001$ & 31.8848 & $<0.0001$ \\
$C 7$ & 3.6144 & 0.0580 & 3.6007 & 0.0578 \\
$C 8$ & 22.0117 & $<0.0001$ & 21.0240 & $<0.0001$ \\
$C 9$ & 44.0837 & 40.0001 & 6.1203 & $<0.0001$ \\
$C 10$ & 6.5231 & 0.0110 & 6.4546 & 0.0111 \\
\hline
\end{tabular}

(1) represents the degrees of freedom of the chi-square distribution and also represents the number of lag periods assumed in the ARCH test.

equation (17) to calculate the stock returns of 10 sample companies. Second, use formula (10) and equation (11) to fit the mean and variance of the 10 stocks' return series, so as to obtain the degree of freedom of $t$ distribution. Thirdly, predict the mean forecast value $\widehat{r_{i, t}}$ and variance forecast value $\widehat{h_{i, t}}$ by the estimation formula one-step forward and substitute the degree of freedom of $t$ distribution and the $95 \%$ confidence level into equation (12) to calculate the value of 10 stock return series at $95 \%$ confidence level. Fourth, combine the return series of 10 stocks in pairs to get 45 combinations and use the DCC-GJR-GARCH $(1,1)$ model of Student $t$ distribution to fit the mean and variance of the return series of these 45 portfolios. At the same time, the return series of the CSI 500 Index and the stock return series as the influencing items are added into the mean estimation formula to obtain the following two formulas:

$$
\begin{aligned}
& r_{j, t}=\beta_{i}+\beta_{j, p} A_{p}(L) r_{j, t-1}+\theta_{j \mid i} r_{i, t}+\varphi_{j} Z Z 500+B_{p}(L) e_{i, t}, \\
& h_{j, t}^{2}=\gamma_{j}+\delta_{j} e_{j, t-1}^{2}+\theta_{j} h_{t-1}^{2}+g I_{t-1} e_{j, t-1}^{2} .
\end{aligned}
$$

Fifthly, predict the mean $\widehat{r_{j, t}}$ and the conditional variance $\widehat{h_{j, t}}$ by the estimation formula one-step forward, substitute the degree of freedom of $t$ distribution and 95\% confidence level into equation (15), and calculate the $\mathrm{CoVaR}_{j \mid i}$ value of 182 combinations at $95 \%$ confidence level.

Sixth, substitute $\mathrm{CoVaR}_{n}$ and $\mathrm{VaR}_{n}$ into equation (16) to get $182 \Delta \mathrm{CoVaR}_{j \mid i}$ values. The results are shown in Table 7.

It can be seen from Table 7 that there is a certain risk spillover effect among securities companies, and the risk spillover effects among different companies are quite different.

In terms of the spread of systemic risks, we can observe that the two largest companies in the industry: Citic Securities Co., Ltd. and China Securities Co., Ltd., have played an important role in spreading risks, and their spreading $\Delta \mathrm{CoVaR}$ values are generally 2-3 units higher than normal level; on the contrary, GF Securities Co., Ltd. and Guotai Junan Securities Co., Ltd. are less likely to spread the risk, and the $\triangle \mathrm{CoVaR}$ value of their spread is about 2-3 units lower than the normal level. The $\Delta \mathrm{CoVaR}$ value spread by other securities companies is at a normal level, and the possibility of spreading systemic risks is moderate. This shows that securities companies with a larger volume have more business volume than other securities companies and have closer business ties with other securities companies. 
TABLE 6: ARCH test of index yield series.

\begin{tabular}{lcccc}
\hline Index & F-statistic & Prob. $F$ & Obs. ${ }^{*} R$-squared & Prob. chi-square (1) \\
\hline All Share Brokerage Index & 12.4252 & 0.0005 & 12.1284 & 0.0005 \\
All Share Financials Index & 6.7539 & 0.0097 & 6.6794 & 0.0098 \\
All Share Insurance Index & 6.4876 & 0.0112 & 6.4200 & 0.0113 \\
CSI Banks Index & 3.0328 & 0.0823 & 3.0255 & 0.0820 \\
CSI 500 Index & 1.6608 & 0.1982 & 1.6621 & 0.1973 \\
\hline
\end{tabular}

(1) represents the degrees of freedom of the chi-square distribution and also represents the number of lag periods assumed in the ARCH test.

TABLe 7: Systemic risk spillover effect among securities companies.

\begin{tabular}{lcccccccccc}
\hline Company & $C 1$ & $C 2$ & $C 3$ & $C 4$ & $C 5$ & $C 6$ & $C 7$ & $C 8$ & $C 9$ & $C 10$ \\
\hline$C 1$ & - & 3.4662 & -1.3785 & -1.3553 & -1.8001 & -2.1605 & -0.4893 & -1.3141 & 4.4979 & -1.6983 \\
$C 2$ & 1.9995 & - & -1.3817 & -1.3435 & -1.8240 & -2.1602 & -0.4932 & -1.2943 & 2.3074 & -1.7109 \\
$C 3$ & -1.2402 & -3.5931 & - & -2.5660 & -3.0181 & -3.3986 & -1.6947 & -2.5270 & 1.0717 & -2.9230 \\
$C 4$ & -0.8427 & -3.3719 & -2.3980 & - & -2.8037 & -3.2142 & -1.4875 & -2.3349 & 1.3047 & -2.6996 \\
$C 5$ & -1.1470 & -3.5429 & -2.5872 & -2.5438 & - & -3.3577 & -1.6521 & -2.5241 & 1.1824 & -2.8921 \\
$C 6$ & -3.0886 & -3.2399 & -2.2559 & -2.2133 & -2.6607 & - & -1.3456 & -2.1608 & 1.4792 & -2.5623 \\
$C 7$ & -1.6651 & -4.3326 & -3.3872 & -3.3400 & -3.7621 & -4.1736 & - & -3.3401 & 0.3833 & -3.6749 \\
$C 8$ & -2.5790 & -3.5359 & -3.7657 & -3.7194 & -4.1760 & -4.5427 & -2.8723 & - & -0.0933 & -4.0720 \\
$C 9$ & -4.2214 & -6.5204 & -5.5533 & -5.4653 & -5.9956 & -6.3541 & -4.6446 & -5.5165 & - & -5.8436 \\
$C 10$ & -6.3236 & -6.4757 & -5.4699 & -5.3562 & -5.8768 & -6.2440 & -4.5635 & -5.2982 & -1.7530 & - \\
\hline
\end{tabular}

They are very important to the securities system and spread systemic risks. The possibility is greater.

In addition, in terms of systemic risk acceptance, we can observe that Shen Wan Hong Yuan Securities Co., Ltd. is more likely to accept the risk and its accepted $\Delta \mathrm{CoVaR}$ value is about 1 unit higher than the normal level; on the contrary, the probability of China Securities Co., Ltd. accepting the risk is very small, much lower than the normal level, and the accepted $\triangle \mathrm{CoVaR}$ value is about 3 units lower than the normal level. The $\Delta \mathrm{CoVaR}$ value accepted by the remaining securities companies is at a normal level, and the possibility of accepting systemic risks is moderate. This shows that the level of risk management of China Securities Co., Ltd. is relatively high, while the level of risk management of Shen Wan Hong Yuan Securities Co., Ltd. is relatively low.

By comparing the differences in risk spread and risk acceptance of different securities companies, it is not difficult to find that there is an asymmetric two-way spillover effect among securities companies; for example, the $\Delta \mathrm{CoV}$ aR value of China Galaxy Securities Co., Ltd. for other securities companies is significantly higher than its accepted $\Delta \mathrm{CoVaR}$ value, generally 3-5 units higher. On the contrary, the risk spillover value accepted by Guotai Junan Securities Co., Ltd. is higher, which is about 2 units higher than the risk spillover value spread by Guotai Junan Securities Co., Ltd. We also find that there is no direct relationship between the size of the company's market value and the risk spillover effect between securities companies; for example, as the two securities companies with the largest market value in the industry, China Securities Co., Ltd. and Citic Securities Co., Ltd. receive the $\triangle \mathrm{CoVaR}$ value from other securities companies at a normal level, or even smaller.

In order to further study the change trend of risk spillover value among securities companies, we draw the time series diagram of systemic risk spillover effect of securities companies (see Figures 1 to 10).
It can be seen from Figures 1 to 10 that the systemic risk spillover effects of different securities companies are quite different, which verifies the analysis results in Table 3. The change trend of risk spillover among securities companies is basically the same, and the abnormal risk spillover mainly occurs in three periods, namely, March 2019 to May 2019, December 2019 to January 2020, and end June to early July 2020.

We compare the trend of the SSE Index (000001. SH), which represents the stock market in China. We can discover that the SSE Index has experienced significant fluctuations in these three periods. From March to May 2019, the market trading sentiment was hot, and the SSE Index rose from about 2600 points to about 3000 points. From December 2019 to January 2020, affected by the epidemic situation, investors did not have confidence in the next market, and the SSE Index plummeted on the first day after the Spring Festival holiday. During this period, the systemic risk spillover phenomenon among securities companies has risen dramatically but is decreased rapidly and maintained at a normal level. From the end of June to the beginning of July, 2020, the stock market entered a hot market again. The SSE index rose from about 3000 points to about 3300 points. The systemic risk spillover effect between securities companies increased rapidly but then quickly dropped to a normal level.

3.7. Analysis of Systemic Risk Spillover Effect between Securities Companies and Financial Industry. Systemic risk spillover effect exists not only between securities companies but also between securities companies and the whole financial industry [32]. Using the calculation method of $\Delta \mathrm{CoVaR}$ between securities companies, we calculate the risk spillover effect between 10 sample securities companies and securities industry (Tables 8 and 9).

It can be seen from Tables 8 and 9 that there is a great asymmetry in the risk spillover between 10 securities 


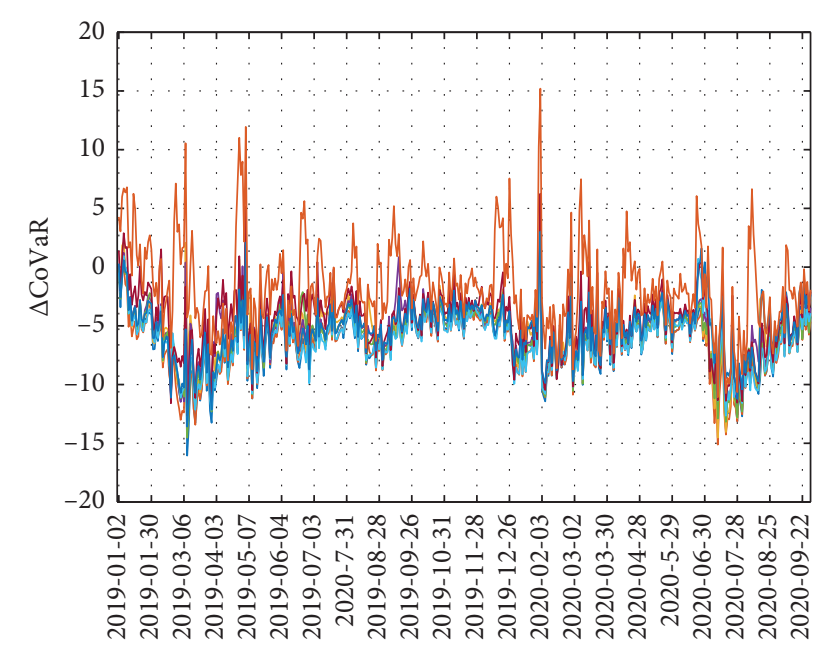

Time

Citic Securities Co., Ltd.

FIgURE 1: Time sequence diagram of systemic risk spillover effect between Citic Securities Co., Ltd. and other securities companies.

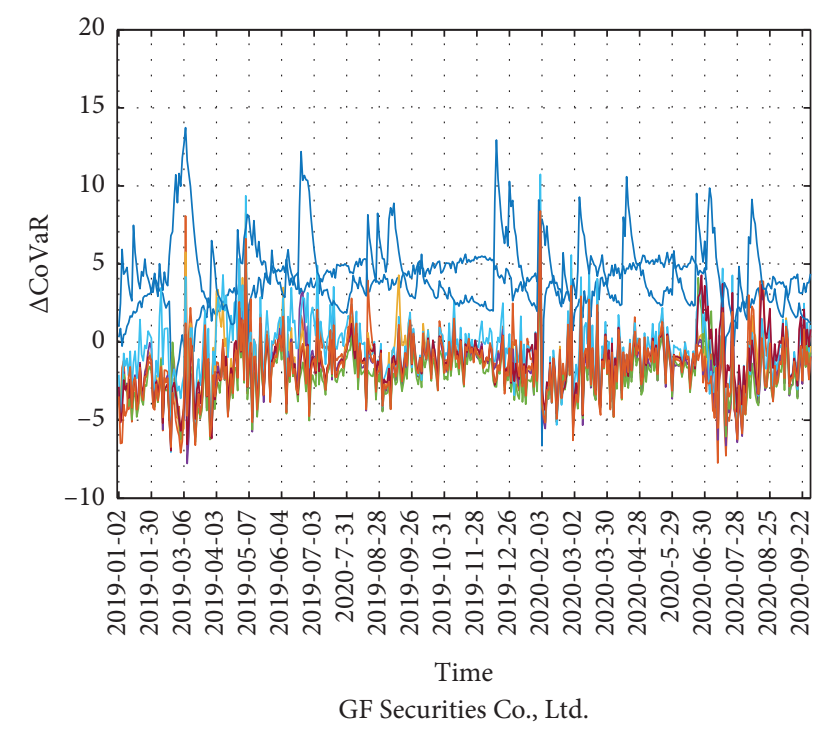

FIGURE 2: Time sequence diagram of systemic risk spillover effect between GF Securities Co., Ltd. and other securities companies.

companies and 4 indexes. On the whole, the risk spillover effects of the 10 securities companies on the four indexes are very large, generally exceeding -2 , while the risk spillover effects of the four indexes on the 10 securities companies are not more than -3.5 . Specifically, the risk spillover effects of 10 securities companies on different indexes are quite different. The $\Delta \mathrm{CoVaR}$ values of ten securities companies on the All Share Financials Index are the largest, followed by the CSI Banks Index, and the $\Delta \mathrm{CoVaR}$ values of the All Share Brokerage Index and the All Share Insurance Index are the smallest.

The risk spillover effects of different securities companies on the same index are also very different; for example, the $\Delta \mathrm{CoVaR}$ values of Citic Securities Co., Ltd. and China

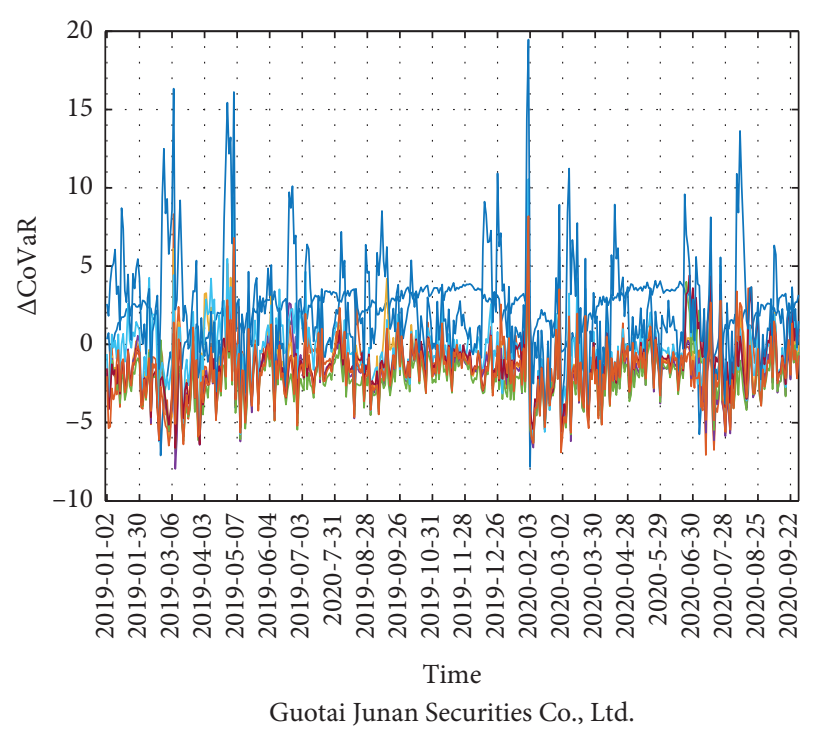

FIGURE 3: Time sequence diagram of systemic risk spillover effect between Guotai Junan Securities Co., Ltd. and other securities companies.

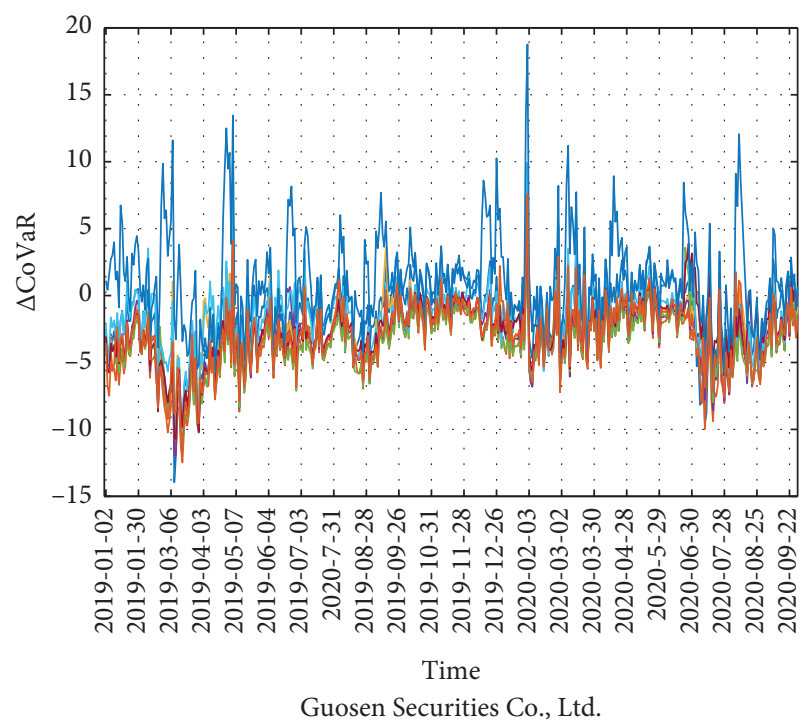

FIgURE 4: Time sequence diagram of systemic risk spillover effect between Guosen Securities Co., Ltd. and other securities companies.

Securities Co., Ltd. to the All Share Financials Index are all in the forefront, both above -7 , while the $\Delta \mathrm{CoVaR}$ values of GF Securities Co., Ltd. and Guotai Junan Securities Co., Ltd. to the All Share Financials Index are relatively small, both below -3.5. The $\Delta \mathrm{CoVaR}$ values of Citic Securities Co., Ltd. and China Securities Co., Ltd. to CSI Banks Index are also very large, all around -7 , while the $\triangle \mathrm{CoVaR}$ values of Guosen Securities Co., Ltd., GF Securities Co., Ltd., and Guotai Junan Securities Co., Ltd. to CSI Banks Index are relatively small, all around -3 .

The risk spillover effects of the four indexes on different securities companies are also very different. The $\Delta \mathrm{CoVaR}$ 


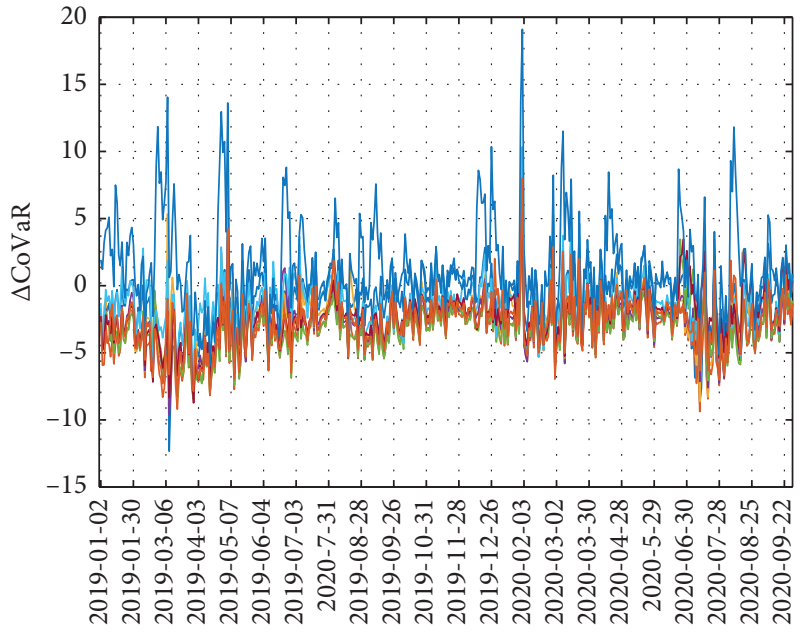

Time

Haitong Securities Co., Ltd.

FIGURE 5: Time sequence diagram of systemic risk spillover effect between Haitong Securities Co., Ltd. and other securities companies.

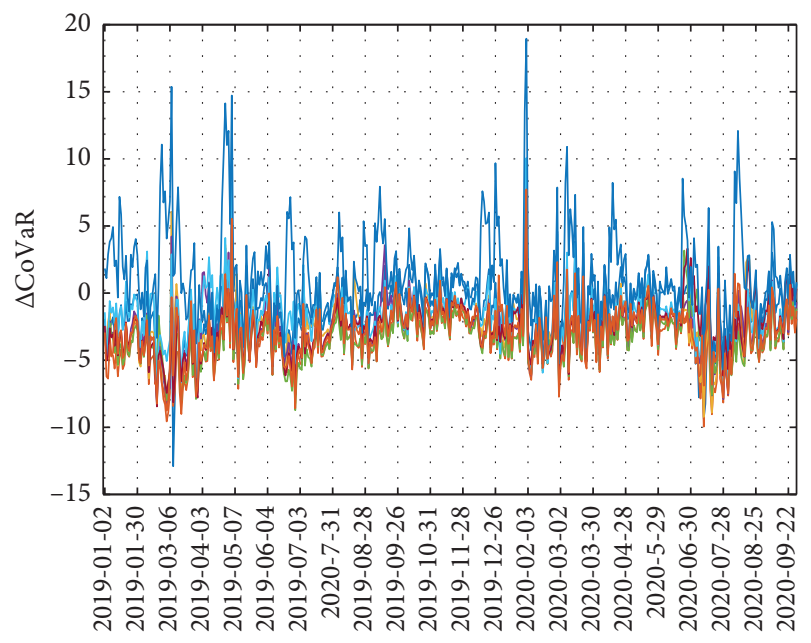

Time

Huatai Securities Co., Ltd.

FIGURE 6: Time sequence diagram of systemic risk spillover effect between Huatai Securities Co., Ltd. and other securities companies.

values of four indexes accepted by China Securities Co., Ltd. are generally large, while those accepted by Guosen Securities Co., Ltd., Citic Securities Co., Ltd., and Haitong Securities Co., Ltd. are generally small.

The risk spillover effects of different indexes on the same securities company are also very different; for example, the $\triangle \mathrm{CoVaR}$ value of All Share Brokerage Index to Shen Wan Hong Yuan Securities Co., Ltd. is very large, which is -3.2906, while the $\Delta \mathrm{CoVaR}$ values of All Share Financials Index, All Share Insurance Index, and CSI Banks Index to Shen Wan Hong Yuan Securities Co., Ltd. are relatively small, not exceeding -1 .

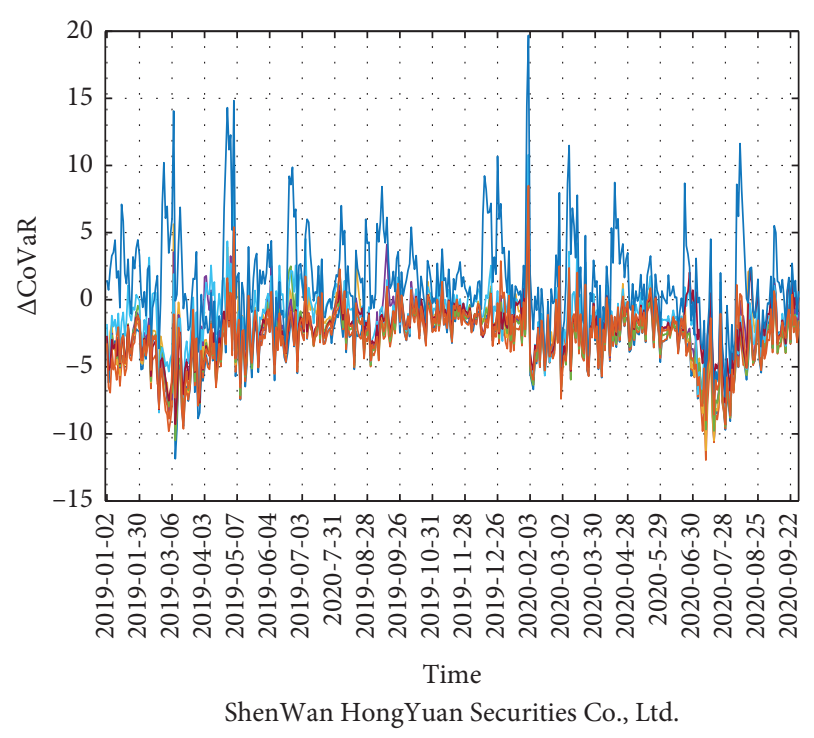

FIGURE 7: Time sequence diagram of systemic risk spillover effect between Shen Wan Hong Yuan Securities Co., Ltd. and other securities companies.

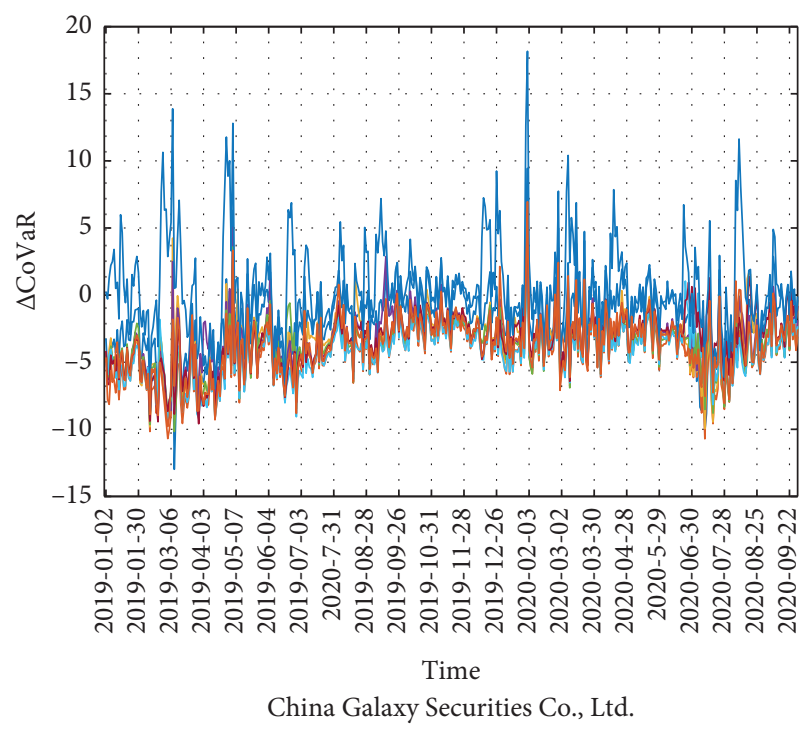

FIgURE 8: Time sequence diagram of systemic risk spillover effect between China Galaxy Securities Co., Ltd. and other securities companies.

3.8. Analysis of Systemic Risk Spillover Effect between Securities Industry and Financial Industry. The lack of liquidity in the financial sector will enhance the contagion of the crisis in financial institutions so that the systemic financial risk may have a significant cross sectoral effect [32, 34].

Using the calculation method of systemic risk spillover effect among securities companies, we calculate the $\Delta \mathrm{CoVaR}$ between All Share Brokerage Index, All Share Financials Index, All Share Insurance Index, and CSI Banks Index. The results are shown in Table 10.

According to Table 10, we can see that the value of risk they absorb and release is very different. 


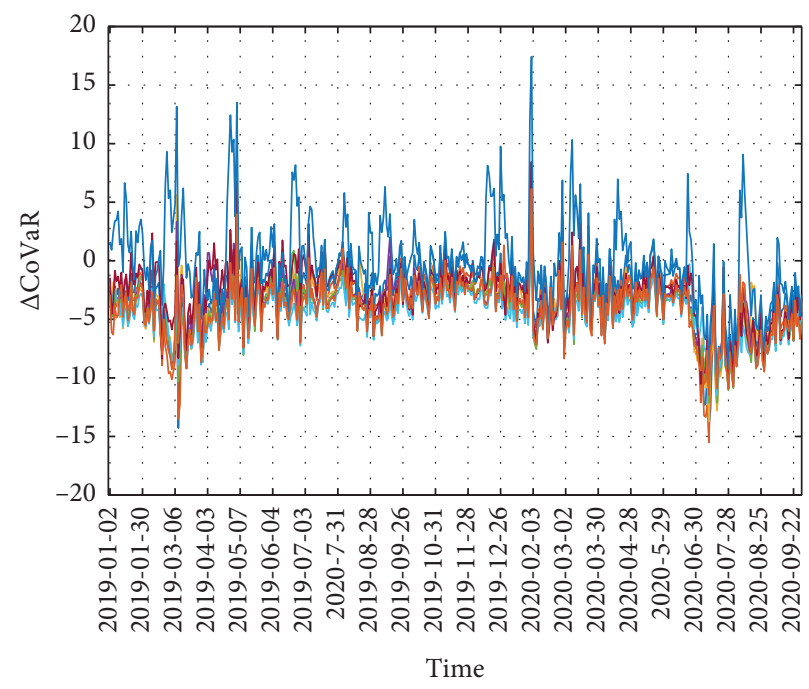

China Merchants Securities Co., Ltd.

Figure 9: Time sequence diagram of systemic risk spillover effect between China Merchants Securities Co., Ltd. and other securities companies.

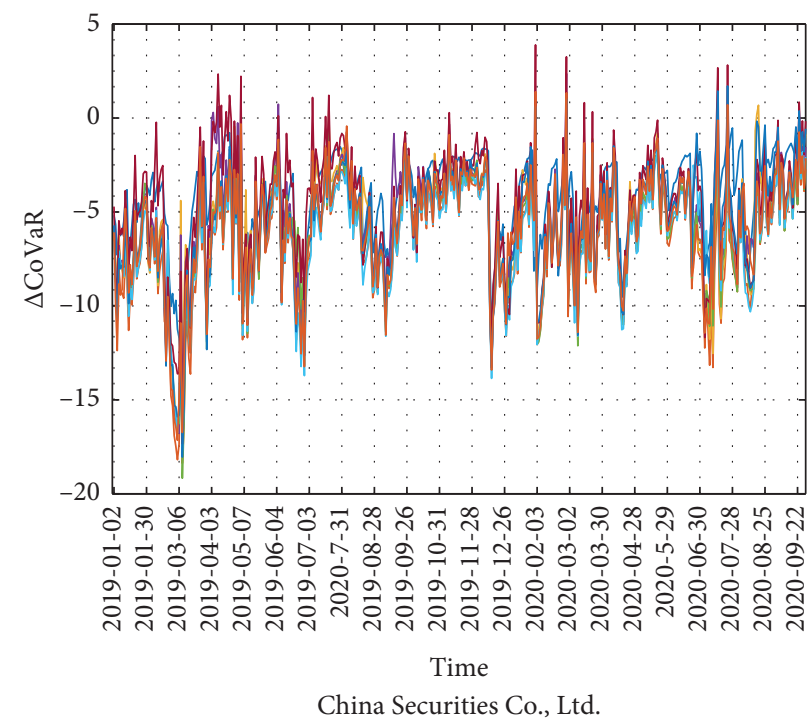

FIgURE 10: Time sequence diagram of systemic risk spillover effect between China Securities Co., Ltd. and other securities companies.

TAвLE 8: Systemic risk spillover effect of securities companies on financial industry.

\begin{tabular}{lcccc}
\hline Company & All Share Brokerage Index & All Share Financials Index & All Share Insurance Index & CSI Banks Index \\
\hline C1 & -2.1002 & -3.2618 & -2.0727 & -2.8704 \\
C2 & -2.1122 & -3.2738 & -2.2152 & -2.8926 \\
C3 & -3.3126 & -4.4787 & -3.4547 & -2.7308 \\
C4 & 0.2696 & -4.2704 & -3.0941 & -3.8690 \\
C5 & -3.2792 & -4.4403 & -2.3884 & -4.0502 \\
C6 & -2.9647 & -4.1224 & -2.9160 & -3.7269 \\
C7 & -4.0540 & -5.2230 & -4.2114 & -4.8225 \\
C8 & -4.4767 & -5.6194 & -4.5852 & -5.2341 \\
C9 & -6.2326 & -7.4462 & -6.2266 & -7.0512 \\
C10 & -6.1807 & -7.3239 & -6.1288 & -6.9540 \\
\hline
\end{tabular}


TABle 9: Systemic risk spillover effect of financial industry on securities companies.

\begin{tabular}{lcccccccccc}
\hline Company & $C 1$ & $C 2$ & $C 3$ & $C 4$ & $C 5$ & $C 6$ & $C 7$ & $C 8$ & $C 9$ & $C 10$ \\
\hline All Share Brokerage Index & -3.3575 & -3.4936 & -2.5053 & 0.6391 & -2.9272 & -3.2906 & -1.6030 & -2.4045 & 1.2224 & -2.8223 \\
All Share Financials Index & -0.8715 & -1.1664 & -0.0259 & 0.0846 & -0.4356 & -0.8119 & 0.8793 & 0.0708 & 3.6705 & -0.3193 \\
All Share Insurance Index & -0.2144 & -1.0981 & -0.1401 & -0.0509 & 2.6363 & -0.9386 & 0.8116 & -0.0910 & 3.5862 & -0.4410 \\
CSI Banks Index & 1.5544 & -0.4496 & 0.5403 & 0.6517 & 0.1554 & -0.2716 & 1.4474 & 0.6205 & 4.2402 & 0.2797 \\
\hline
\end{tabular}

TABLE 10: Systemic risk spillover effect between securities industry and financial industry.

\begin{tabular}{lcccc}
\hline & All Share Brokerage Index & All Share Financials Index & All Share Insurance Index & CSI Banks Index \\
\hline All Share Brokerage Index & - & -4.3827 & -3.1805 & -3.9966 \\
All Share Financials Index & -0.7314 & - & -0.6777 & -1.5126 \\
All Share Insurance Index & -0.8112 & -1.9923 & - & -1.5959 \\
CSI Banks Index & -0.1638 & -1.3131 & -0.1043 & - \\
\hline
\end{tabular}

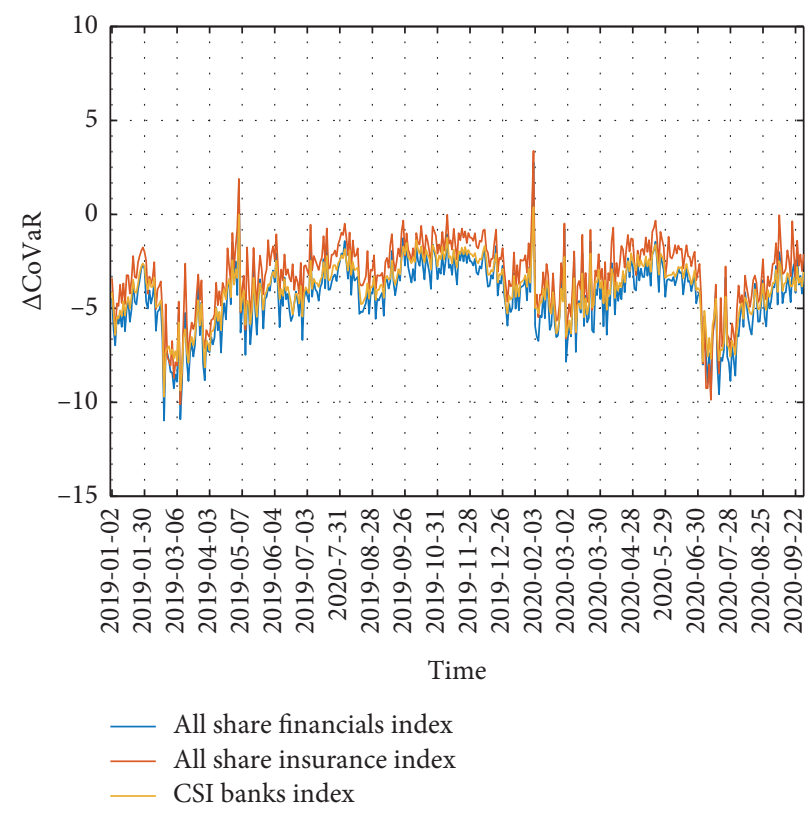

FIgURE 11: Time series of risk spillover effect of securities industry on financial industry.

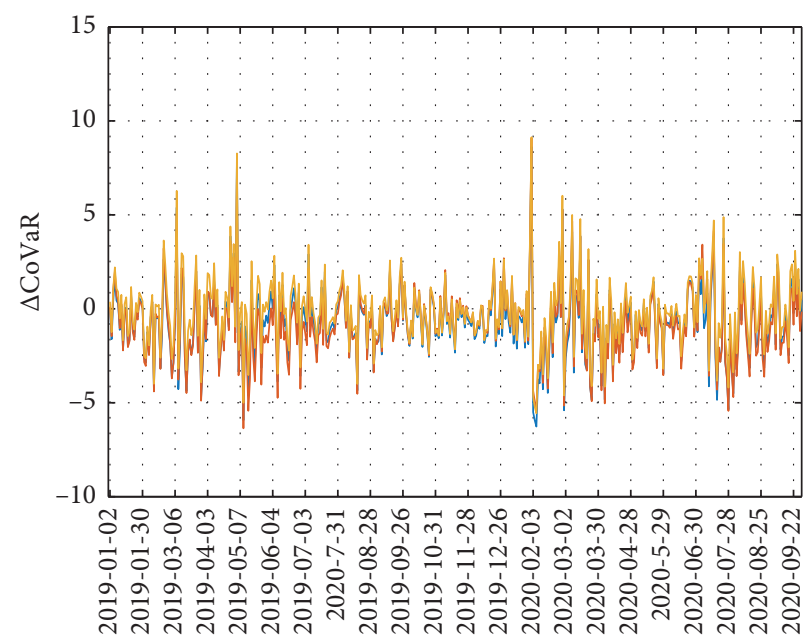

Time

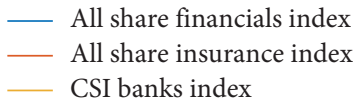

FIgURE 12: Time series of risk spillover effect of financial industry on securities industry. 
The securities industry receives relatively small risk spillovers from the other three indexes, generally around -0.7 . Among them, the banking industry has minimal risk spillovers to the securities industry, which is -0.1638 , followed by the entire financial industry, and the insurance industry has the largest risk spillover, which is -0.8112 . However, the risk spillover value released by the securities industry is very high, generally around -4 . Among them, the securities industry releases the largest risk spillover value to the entire financial industry, which is -4.3827 , the risk spillover value to the banking industry is the second, and the risk spillover value to the insurance industry is the smallest [35].

In order to directly depict the risk spillover effects between industries, this paper draws the time series diagrams of the two-way risk spillover effects between the securities industry and the financial subsectors (Figures 11 and 12).

It can be seen from Figures 11 and 12 that the change trend of risk spillover effect between indexes is similar to that between securities companies, and there are also large fluctuations in the following three periods, namely, March 2019 to May 2019, December 2019 to January 2020, and end June to early July 2020.

In addition, we found that the securities department received less risk but spread greater risk to the system.

\section{Conclusions and Suggestions}

This paper selects the top 10 securities companies by market value in China, All Share Brokerage Index, All Share Financials Index, All Share Insurance Index, and CSI Banks Index as the research objects, uses the DCC-GJR-GARCH model to calculate the risk spillover values among the research objects, and draws the sequence chart of systemic risk spillover according to the results, so as to explore the change rules and reasons of systemic risk spillover effect of Chinese securities companies. The conclusions are as follows: (1) there are risk spillover effects among 10 securities companies which are asymmetric and bidirectional and highly volatile in a short period of time; (2) the spillover effect of systematic risk of securities companies has no directly relationship with the market value of securities companies but has a strong relationship with the stock market; (3) there are risk spillover effects between the sample securities companies and the four major indexes, and the difference of these effect values is obvious; (4) the risk spillover effect of securities industry on other financial sectors is great, but on the contrary, it is very small.

Based on this, we put forward the following suggestions: (1) implement differentiated risk supervision measures for different types of securities companies to improve the flexibility of risk supervision; (2) steadily advance the reform of the securities industry and stabilize the fluctuation of market trading sentiment; (3) control the scale and quantity of securities companies and reduce the possibility of systemic risk infection; (4) promote the accuracy of systematic risk measurement and enhance the ability of systematic risk identification.

\section{Data Availability}

The data used to support the findings of this study are included within the article.

\section{Conflicts of Interest}

The authors declare that there are no conflicts of interest regarding the publication of this paper.

\section{Acknowledgments}

This work was supported by the project of National Innovation and Entrepreneurship Training Program for College Students (no. 202010378042) and the project of Anhui University Humanities and Social Sciences Research (no. SK2020A0011).

\section{References}

[1] F. Yang, "The development status and problems of securities industry in China," Management and Administration, vol. 12, pp. 112-114, 2019.

[2] J. Lai, Research of the Financial Systemic Risk of China and It's Prevention, Jiangxi University of Finance \& Economics, Nanchang, China, 2011.

[3] S. Benoit, J.-E. Colliard, fnm Hurlin, and C. Pérignon, "Where the risks lie: a survey on systemic risk*," Review of Finance, vol. 21, no. 1, pp. 109-152, 2017.

[4] X. P. Zhang, "A study on systemic financial risk:evolution, causes and supervision," Studies of International Finance, vol. 7, pp. 58-67, 2010.

[5] F. Allen and D. Gale, "Financial contagion," Journal of Political Economy, vol. 108, no. 1, pp. 1-33, 2000.

[6] V. V. Acharya, L. H. Pedersen, T. Philippon, and M. Richardson, "Measuring systemic risk," Review of Financial Studies, vol. 30, no. 1, pp. 2-47, 2017.

[7] T. Adrian and M. K. Brunnermeier, "CoVaR," American Economic Review, vol. 106, no. 7, pp. 1705-1741, 2016.

[8] X. M. Bai and D. L. Shi, "Measurement of the systemic risk of China's financial system," Studies of International Finance, vol. 6, pp. 75-85, 2014.

[9] R. Roengpitya and P. Rungcharoenkitkul, "Measuring systemic risk and financial linkages in the Thai banking system," Systemic Risk, Basel III, Financial Stability and Regulation, Florence, Italy, 2011.

[10] Z. H. Li and L. Fan, "Empirical study on systemic risk spillover of China commercial banks," Modern Economic Science, vol. 6, pp. 13-20, 2011.

[11] C. Gauthier, A. Lehar, and M. Souissi, "Macroprudential capital requirements and systemic risk," Journal of Financial Intermediation, vol. 21, no. 4, pp. 594-618, 2012.

[12] M. Bernardi, A. Maruotti, and L. Petrella, "Skew mixture models for loss distributions: a Bayesian approach," Insurance: Mathematics and Economics, vol. 51, no. 3, pp. 617-623, 2012.

[13] H. C. Lin, T. Liu, and P. Y. Zhang, "Empirical study on systemic risk spillover effect of insurance institutions-_based on the AR-GARCH-CoVaR model," in Deepen Reform, Seek Progress in Stability: The Perspective of Insurance and Social Security-CCISSR Forum 2012, pp. 310-324, Springer, Berlin, Germany, 2012. 
[14] G. Girardi and A. Tolga Ergün, "Systemic risk measurement: multivariate GARCH estimation of CoVaR," Journal of Banking \& Finance, vol. 37, no. 8, pp. 3169-3180, 2013.

[15] J. C. Reboredo and A. Ugolini, "Systemic risk in European sovereign debt markets: a CoVaR-copula approach," Journal of International Money and Finance, vol. 51, pp. 214-244, 2015.

[16] W. K. Härdle, W. Wang, and L. Yu, "Tenet: tail-event driven network risk," Journal of Econometrics, vol. 192, no. 2, pp. 499-513, 2016.

[17] H. Xu, M. X. Wei, and X. Chen, "A research on the systemic risk of insurance sector and influencing factors financial stability under the risk interconnected perspective," Insurance Studies, vol. 11, pp. 3-15, 2016.

[18] W. Yuan and P. H. Wang, "Research on systemic risk spillover effects of insurance companies--based on the DCCGARCH-CoVaR model," Finance and Accounting Monthly, vol. 5, pp. 114-118, 2017.

[19] H. Long, J. Zhang, and N. Tang, "Does network topology influence systemic risk contribution? A perspective from the industry indices in Chinese stock market," PLoS One, vol. 12, no. 7, 2017.

[20] Z. H. Yang, Y. T. Chen, and R. K. Xie, "Research on systemic risk measures and cross-sector risk spillover effect of financial institutions in China," Journal of Financial Research, vol. 460, no. 10, pp. 19-37, 2018.

[21] Z. Li, X. F. Tu, and L. Bu, "Systemic risks of financial institutions:importance and vulnerability," Journal of Finance and Economics, vol. 45, no. 2, pp. 100-112, 2019.

[22] H. Y. Wang and K. Yang, "An empirical study on the spillover effects of the stock markets along the Belt and Road based on EVT-copula-CoVaR model," Journal of Financial Development Research, vol. 9, pp. 79-85, 2019.

[23] Q. Xu, M. Li, C. Jiang, and Y. He, "Interconnectedness and systemic risk network of Chinese financial institutions: a LASSO-CoVaR approach," Physica A: Statistical Mechanics and Its Applications, vol. 534, p. 122173, 2019.

[24] X. F. Zhang and L. B. Xu, "Financial derivatives and banking systemic risks," Studies of International Finance, vol. 393, no. 1 , pp. 76-85, 2020.

[25] A. K. Tiwari, N. Trabelsi, fnm Alqahtani, and I. D. Raheem, "Systemic risk spillovers between crude oil and stock index returns of G7 economies: conditional value-at-risk and marginal expected shortfall approaches," Energy Economics, vol. 86, p. 104646, 2020.

[26] M. Wang, A Study on the Dynamic Correlation among Spot,Futures and Stock Markets Using Trivariate DCC-GJRGARCH Model-CThe case of Steel Industry, Zhejiang University of Finance and Economics, Hangzhou, China, 2019.

[27] Y. Jiang and S. G. Xing, "Dynamic analysis of foreign exchange reserve's exchange rate risk based on DCC-GARCHCVaR model," The Theory and Practice of Finance and Economics, vol. 31, no. 2, pp. 16-20, 2010.

[28] T. Adrian and M. K. Brunnermeier, Covar, NBER Working Papers, New York, NY, USA, 2001.

[29] L. R. Glosten, R. Jagannathan, and D. E. Runkle, "On the relation between the expected value and the volatility of the nominal excess return on stocks," The Journal of Finance, vol. 48, no. 5, pp. 1779-1801, 1993.

[30] L. W. Lv, The Study on DCC-MVGARCH Model and Empirical Analysis in Financial Market, Jinan University, Guangzhou, China, 2006.
[31] Z. J. Zhou, "Analysis of the risk of mutual fund using VaR method based on GARCH model in China," Business Management Journal, vol. 22, pp. 46-49, 2006.

[32] R. F. Engle, "Autoregressive conditional heteroskedasticity with estimates of the variance of United Kingdom inflation," Econometrica, vol. 50, pp. 987-1007, 1982.

[33] H. Pang, Econometrics, Science Press, China, 2019.

[34] Y. R. Liu, Estimate of the Systemic Risk of China's Securities Industry through CoVaR Method, Xiamen University, Xiamen, China, 2014.

[35] J.-M. Zhu, L. Wang, and J.-B. Liu, "EradicationofEbolabased on dynamic programming," Computational and Mathematical Methods in Medicine, vol. 2016, p. 9, Article ID 1580917, 2016. 